\title{
MORFOLOGIA DA PLATAFORMA CONTINENTAL DO MUNICÍPIO DE LUÍS CORREIA - PIAUÍ
}

\author{
Jeziel Pena Forte Lopes ${ }^{1}$ \\ Jéssica Patrícia Capistrano Lins ${ }^{1}$ \\ João Capistrano de Abreu Neto ${ }^{2}$ \\ Daniel de Ponti Souza ${ }^{3}$ \\ George Satander Sá Freire ${ }^{4}$
}

10.18190/1980-8208/estudosgeologicos.v28n2p99-107

${ }^{1}$ Programa de Pós-graduação em Geologia - UFC. jeziel-lopes@ hotmail.com ; jehpah@hotmail.com

${ }^{2}$ Doutor em Geologia - UFC. joaoabreuneto@gmail.com

${ }^{3}$ Mestre em Geologia - UFC. danieldeponti@ hotmail.com

${ }^{4}$ Laboratório de Geologia Marinha e Aplicada (LGMA/UFC) - Departamento de

Geologia - UFC. $\underline{\text { freire@ ufc.br }}$

\section{RESUMO}

A área de estudo está localizada na plataforma continental do município de Luís Correia, no estado do Piauí, região ainda pouco estudada, no contexto da bacia do Ceará, especificamente a sub-bacia do Piauí-Camocim. Dada à falta de estudos nesta área, foi considerado importante realizar uma caracterização morfológica da plataforma continental de Luís Correia. Para desenvolver este trabalho foram utilizadas imagens do satélite Landsat 8 para identificação das formas de fundo. Adquiridas no site do INPE, as imagens foram gravadas, filtradas e interpretadas nos softwares ArcGIS 10 e Envi 4.8, com a correção geométrica com base nas imagens do Geocover. Foram também utilizados dados batimétricos extraídos da base de dados ETOPO-1 no site NOAA, os quais foram validados de acordo com as cartas náuticas da Diretoria de Hidrografia e Navegação (DHN). Com os dados batimétricos foram traçados dois perfis, um na costa leste, outro na costa oeste da área e a elaboração de um mapa de declividade. Com isso, foi possível identificar algumas estruturas como os paleocanais associados à foz do rio Parnaíba e rio Portinho. Através dos perfis foi possível compartimentar a plataforma em interna, média e externa com a zona de quebra da plataforma continental ocorrendo a cerca de $80 \mathrm{~km}$ do continente. Exibe inclinação menor que $1^{\circ}$, pequenas variações ocorrendo, sendo a maior variação na plataforma externa e na zona de quebra da plataforma, onde a declividade muda abruptamente para uma inclinação de $8,5^{\circ}$, variação esta que ocorre a $80 \mathrm{~km}$ da linha de costa. Recomenda-se um estudo batimétrico mais detalhado para a melhor caracterização das feições submersas identificadas na área.

Palavras-chave: morfologia, imagens de satélite, dados batimétricos.

\begin{abstract}
The study area is located on the continental shelf of the municipality of Luís Correia, in the state of Piauí, a region not yet studied, in the context of the Ceará basin, specifically the Piauí-Camocim sub-basin. Due to the lack of studies in this area, it was considered important to carry out a morphological characterization of the continental shelf of Luís Correia. To develop this work, images of the Landsat 8 satellite were used to identify the background shapes. Acquired on the INPE website, images were recorded, filtered and interpreted in ArcGIS 10 and Envi 4.8 software, with geometric correction based on Geocover images. Bathymetric data extracted from the ETOPO-1 database on the NOAA
\end{abstract}


website were also used, which were validated according to the nautical charts of the Hydrographic and Navigation Department (DHN). With the bathymetric data, two profiles were drawn, one on the east coast, the other on the west coast of the area and the elaboration of a slope map. With this, it was possible to identify some structures such as the paleochannels associated with the mouth of the river Parnaíba and Portinho river. By mean of the profiles it was possible to categorize the platform in inner, medium and outer with the continental shelf break zone taking place around $80 \mathrm{~km}$ from the continent. It shows a slope smaller steepness than $1^{\circ}$, small variations occurring, being the greater variation in the outer platform and the zone of break of the platform, where the slope changes abruptly to a $8.5^{\circ}$ steep. A more detailed bathymetric study is recommended to better characterize the submerged features identified in the area.

Keywords: morphology, satellite images, bathymetric data.

\section{INTRUDUÇÃO}

Segundo Baptista Neto \& Silva (2004), as margens continentais do tipo Atlântico, como no caso da margem brasileira, apresentam uma fisiografia bem definida dividida em três províncias distintas: a plataforma continental, o talude continental e a elevação ou sopé continental.

A Plataforma Continental, característica das margens continentais do tipo atlântico, apresenta normalmente gradientes de elevação suaves, inferiores a 1:1000, abrangendo a linha de costa até uma mudança brusca, onde há um aumento do gradiente topográfico, chamada de quebra da plataforma (Suguio, 2003; Baptista Neto \& Silva, 2004). A morfologia é resultado do efeito acumulativo dos processos cíclicos de erosão e deposição em relação às constantes oscilações no nível do mar conforme mostra Kennet (1982) e Suguio (2003).

Os trabalhos realizados na área têm como foco a granulometria e geoquímica dos sedimentos da plataforma (Dias et al. 2011; Aguiar, 2014), e tal ausência de estudos sobre a morfologia da Plataforma Continental do Piauí, torna este trabalho importante do ponto de vista econômico para identificação de depósitos de sedimentos e do ponto de vista científico através das variações do nível do mar que ficam marcadas na plataforma.

Dessa maneira, este trabalho tem como objetivo caracterizar morfologicamente a plataforma continental do município de Luís Correia, bem como sua subdivisão, através do uso de mapas batimétricos e fotografias aéreas.

\section{MATERIAL E MÉTODOS}

\section{Área de estudo}

Está localizada no litoral do município de Luís Correia, estado do Piauí. (Fig.1). Geologicamente está inserida na porção oeste da bacia do Ceará, sub-bacia de Piauí-Camocim. 


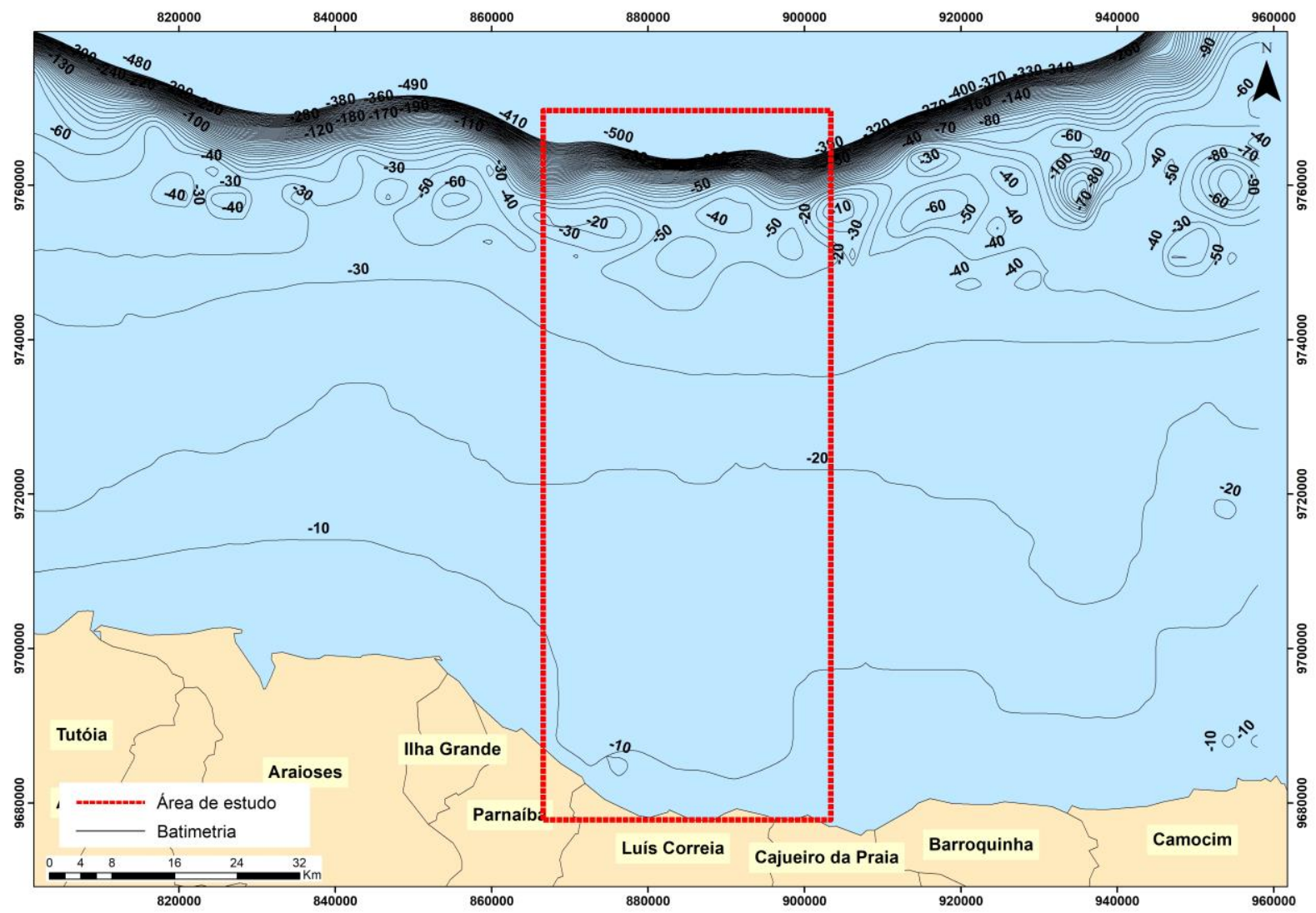

Figura 1 - Localização da área de estudo e batimetria da PCPI entre os municípios de Tutóia e Camocim (Fonte: Os autores).

\section{Método}

A metodologia consistiu no levantamento de imagens digitais do Landsat 8 e Geocover, além de dados batimétricos. O processamento destas imagens e dados encontra-se descrito a seguir.

\section{SENSORIAMENTO REMOTO}

O sensor utilizado para obtenção de imagens foi o Landsat 8 (órbita 219/ ponto 62), de 12 de julho de 2016, na faixa espectral da banda 2. As imagens foram baixadas do site do INPE (Instituto Nacional de Pesquisas Espaciais) utilizando a tábua de maré como critério determinante para seleção, onde as mesmas foram escolhidas em períodos de maré baixa e sem cobertura de nuvens na região da plataforma continental.

As imagens de satélite foram registradas, filtradas e interpretadas, onde o registro teve como referencial geométrico as imagens Geocover no software ArcGis 10.3 com a extensão georreferencing. No software Envi 4.8, foi aplicado um filtro direcional de $90^{\circ} \mathrm{e}$ aplicação de um filtro de passa baixa com máscara de 7 pixels na imagem.

\section{BATIMETRIA}

Os dados batimétricos usados nesta pesquisa foram extraídos do banco de dados ETOPO-1 no site NOAA, com resolução de um arco/segundo. As quais foram validadas de acordo com as folhas de bordo da Diretoria de Hidrografia e Navegação (DHN).

Estes dados foram processados no software ArcGis 10.3, onde foi utilizada a ferramenta Contour para geração de curvas batimétricas com intervalos de 10 metros e a ferramenta Smooth Line para suavização das mesmas. Foram geradas linhas com isóbatas de -100 metros de forma que fosse possível a identificação da quebra da plataforma. 
Com a batimetria foram traçados dois perfis batimétricos e gerado um mapa de declividade na área do projeto.
A figura 2 espacializa a área do litoral de Luís Correia e a localização dos perfis que foram traçados.

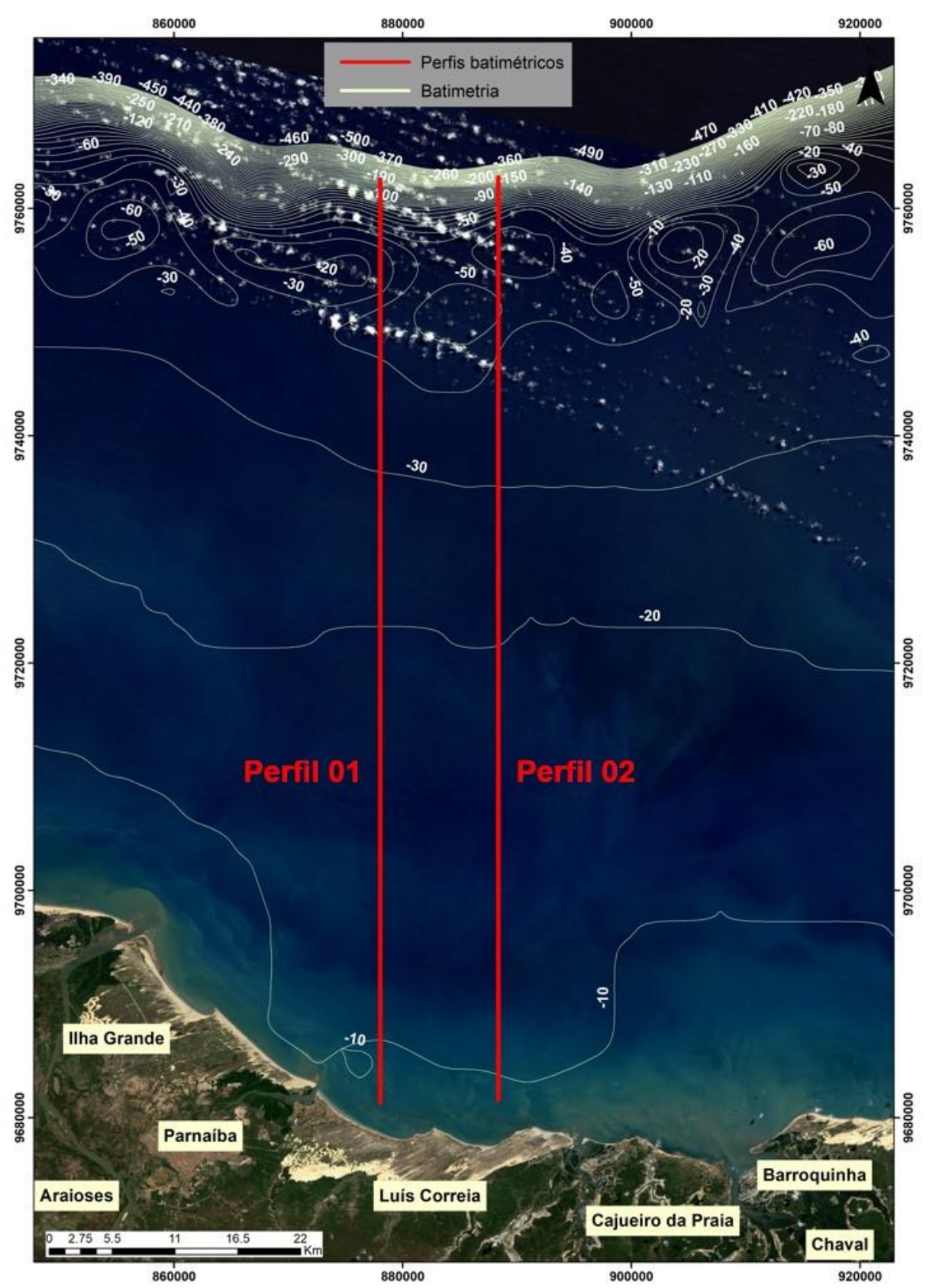

Figura 2 - Localização dos perfis batimétricos em Luís Correia (Fonte: INPE).

\section{GEOLOGIA REGIONAL}

A Bacia do Ceará (Fig. 3) está localizada na margem equatorial brasileira, abrangendo uma área de aproximadamente $\quad 34.000 \quad \mathrm{~km}^{2}$, limitando-se a sudeste com a Bacia Potiguar pelo Alto de Fortaleza, e a oeste limita-se com a Bacia de Barreirinhas pelo Alto de Tutóia. O limite sul é dado pela faixa de afloramento do embasamento cristalino, junto à linha de costa, enquanto ao norte limita-se pelo ramo sul da Zona de Fratura Romanche (Costa et al., 1989).

Tem sua gênese relacionada ao rompimento do supercontinente Gondwana e, provavelmente, iniciou sua 
evolução no Eoaptiano (Costa et al., 1989; Beltrami et al., 1994). Tal inferência dá-se a partir da grande espessura de sedimentos, ainda não atingido por poços, sob a seção aptiana da bacia e pela considerável espessura de rochas sedimentares paleozoicas e mesozoicas presentes na Bacia de Keta, que é considerada sua contraparte africana (Costa et al., 1989).

Costa et al. (1989) e Beltrami et al. (1994) reconhecem três estágios tectonosedimentares na bacia, cada qual tendo sido responsável pela deposição de sequências litoestratigráficas correspondentes: fase rifte, fase transicional (ou pós-rifte) e fase drifte. Cada fase de evolução da bacia apresenta sua conformação estrutural específica que propiciou uma mudança cíclica de ambientes deposicionais, gerando assim uma litoestratigrafia que registra cada momento da evolução e que guarda uma correlação com a Bacia Potiguar.

Devido a características tectônicas distintas e feições estruturais proeminentes, a Bacia do Ceará foi subdividida em quatro sub-bacias que são, de leste para oeste, Mundaú, Icaraí, Acaraú e Piauí-Camocim (Costa et al., 1990).

As sub-bacias de Piauí-Camocim, Acaraú e Icaraí constituem a parte oeste da bacia do Ceará, que engloba ainda a sub-bacia de Mundaú compondo a parte leste. Estas localizam-se na margem equatorial brasileira, ao longo do litoral dos estados do Piauí e do Ceará (Beltrami et al., 1989). As sub-bacias Piauí-Camocim e Acaraú estão separadas pelo Alto do Ceará, a subbacia de Icaraí, por sua vez, está separada da sub-bacia de Acaraú pelo prolongamento norte do Lineamento de Sobral-Pedro II, segmento norte do Lineamento Transbrasiliano e as subbacias de Mundaú e Icaraí estão separadas por uma inflexão da falha de borda da bacia, no prolongamento nordeste da falha de Forquilha (Morais Neto et al., 2003).

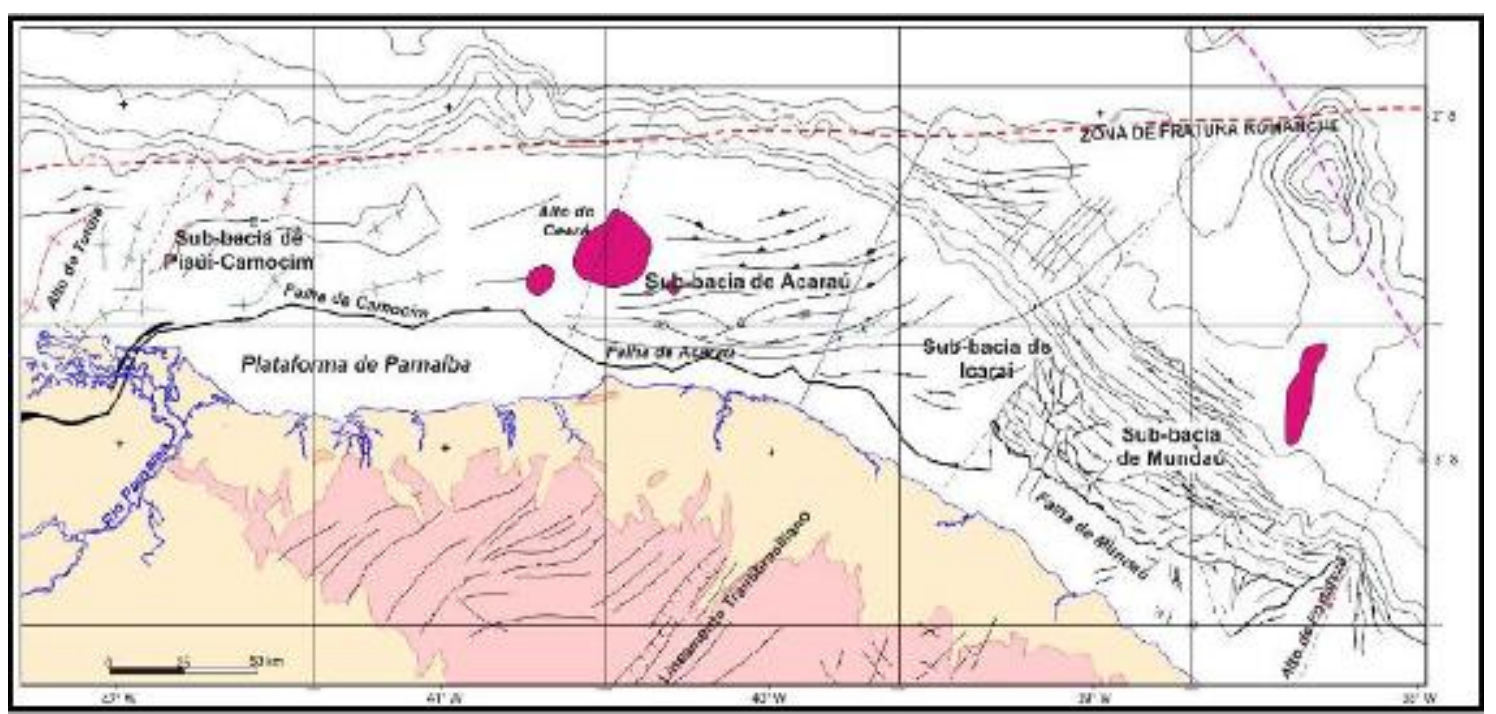

Figura 3 - Localização, limites e arcabouço da Bacia do Ceará (Fonte: Morais Neto et al., 2003). 


\section{RESULTADOS E DISCUSSÃO}

A identificação da morfologia da plataforma procedeu-se a partir de interpretação visual de imagem de satélite em conjunto com a informação dos dados batimétricos. A análise da imagem (Fig. 4) permitiu identificar um paleocanal com extensão de aproximadamente 35 quilômetros, associado ao rio Portinho, com direção perpendicular à linha de costa, sugerindo um canal submerso, o qual pode ser testemunho do vale do rio em época de recuo do nível do mar, fazendo com que os rios adentrem até o que hoje é descrito como plataforma média.

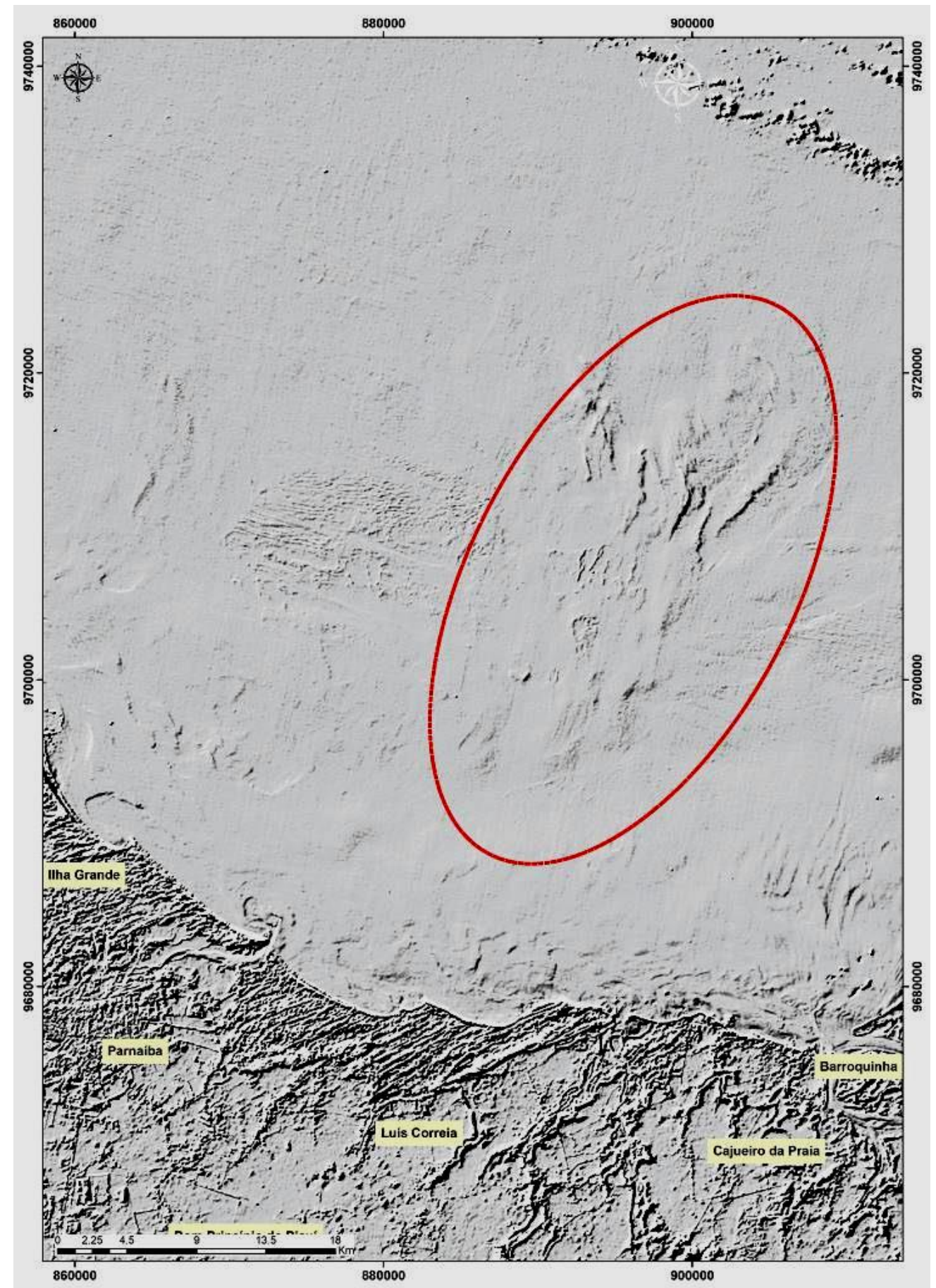

Figura 4 - Orbita 213-62, satélite Landsat 8, banda 2, em destaque o canal submerso (Fonte: Os autores). 
De acordo com o mapa de declividade (Fig. 5) a plataforma possui declividade inferior a $1^{\circ}$, não ocorrendo grandes variações, no entanto, ao fim da plataforma externa observa-se uma mudança de declividade para cerca de $8,5^{\circ}$. Essa mudança marca a quebra da plataforma para o talude continental, sabe-se que o talude é a região dos fundos marinhos com declive muito pronunciado.

Através da análise dos perfis batimétricos (Fig. 6 e 7) foi possível identificar a compartimentação da plataforma continental, onde devido a sua morfologia foram subdivididas em plataforma interna, média e externa:

a) Plataforma interna, que vai de 0 a 20 metros de profundidade, com o relevo aproximadamente regular, apresentando declividade média de $0,5^{\circ}$. É a porção com maior influência de sedimentos terrígenos, devido à proximidade da linha de costa;

b) Plataforma média, que é limitada pelas isóbatas de 20 a 40 metros, apresentando o relevo mais plano da plataforma com declividade média de $0,02^{\circ}$, sendo o canal submerso a feição predominante da área;

c) Plataforma externa, a partir de 40 metros, o relevo mais irregular, onde se forma uma pequena depressão, com aproximadamente 3 quilômetros de extensão. A offshore observa-se a quebra da plataforma, que se apresenta de forma abrupta, com declividade média de $8,5^{\circ}$ e ocorrendo cerca de 80 $\mathrm{km}$ da linha de costa.

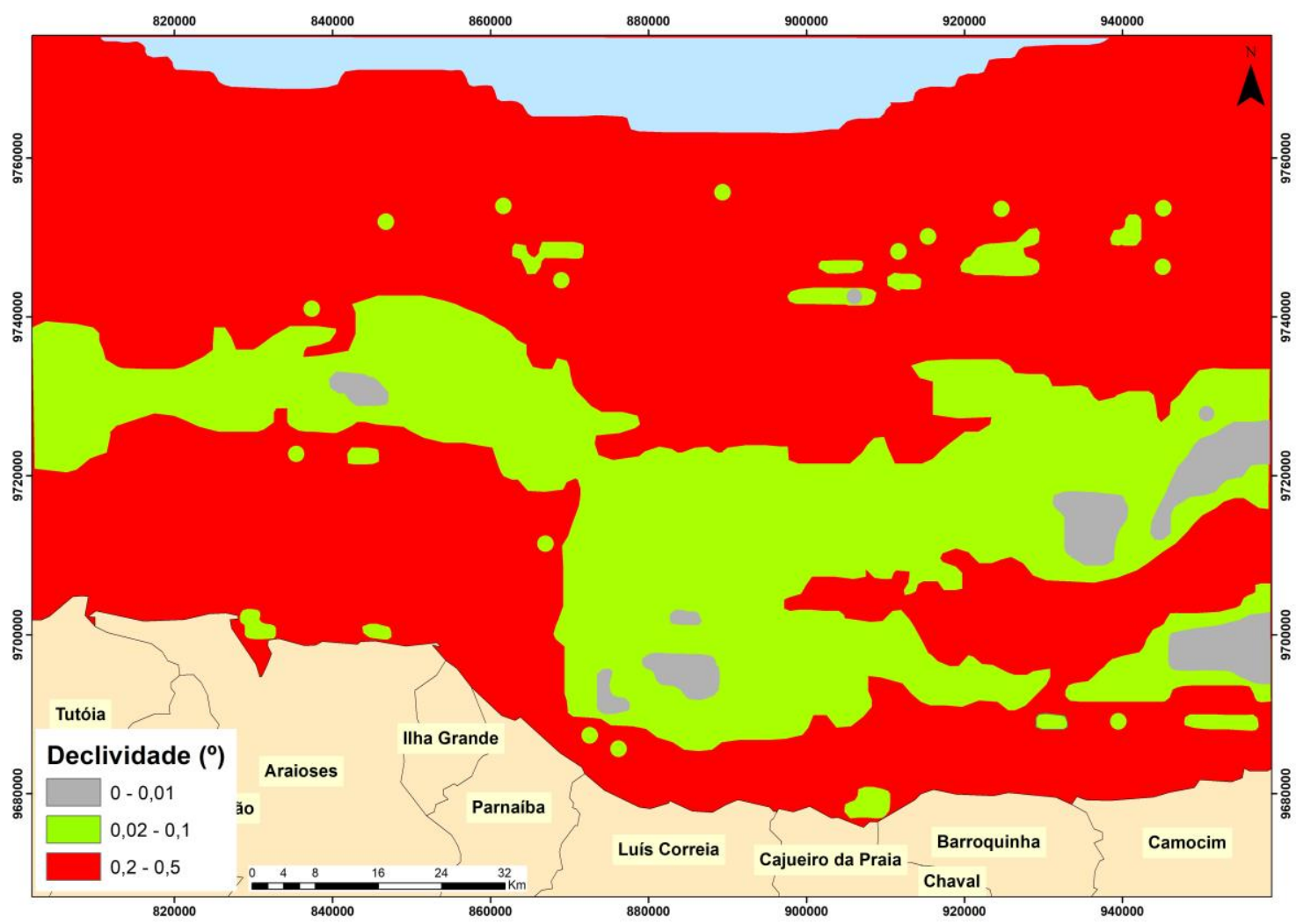

Figura 5 - Mapa de declividade do litoral entre os municípios de Tutóia e Camocim (Fonte: Os autores). 


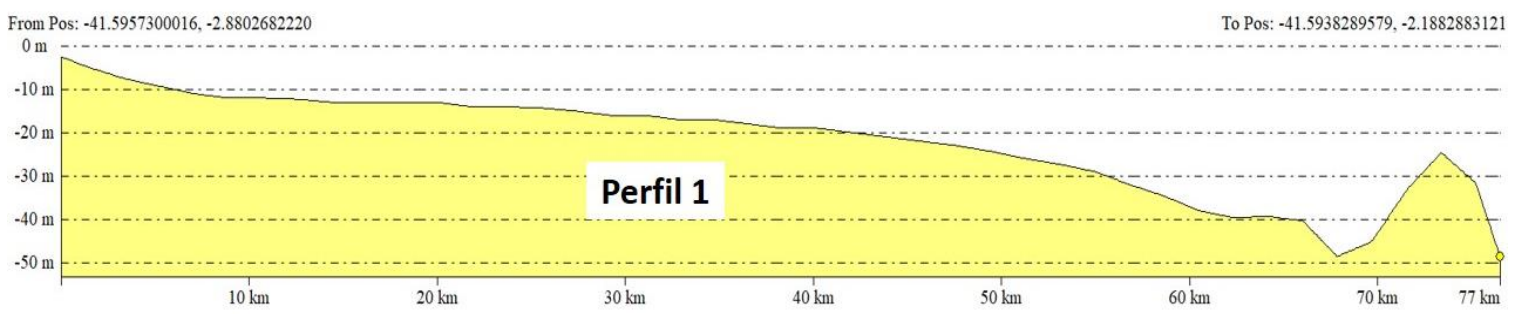

Figura 6 - Perfil batimétrico da porção oeste da plataforma continental do município de Luís Correia - PI

(Fonte: Os autores).

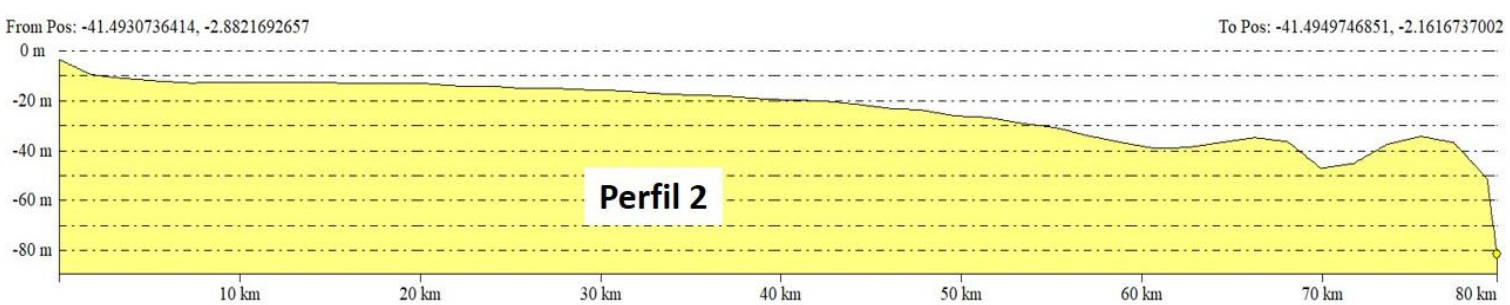

Figura 7 - Perfil batimétrico da porção leste da plataforma continental do município de Luís Correia - PI (Fonte: Os autores).

De acordo com o que foi apresentado nos perfis, fica bem evidente a diferença morfológica de cada setor da plataforma e na plataforma externa ainda puderam ser vistas diferenças como uma elevação da zona de quebra, fazendo com que a mesma ocorra por volta dos 30 metros de profundidade, o que representa uma profundidade relativamente rasa, que pode ser resultante de influência fluvial. Recomenda-se um estudo batimétrico mais detalhado, em escala de 1: 100.000 ou maior para uma melhor caracterização das feições submersas.

\section{CONCLUSÕES}

A utilização conjunta de imagens de satélite e produtos de dados batimétricos como mapa de isóbatas, perfis batimétricos e mapa de declividade apresentou resultados satisfatórios para uma caracterização morfológica inicial da plataforma continental do município de Luís Correia - PI, tornando possível a identificação de feições submersas como a quebra da plataforma e os canais submersos, a compartimentação da plataforma de acordo com sua morfologia e seus limites geográficos.

Foi possível identificar os paleocanais associados à foz do rio Parnaíba e rio Portinho, que apresentam uma extensão de aproximadamente 30 quilômetros e sentido SO-NE. Através dos perfis foi possível compartimentar a plataforma em interna, média e externa com a zona de quebra da plataforma continental ocorrendo a cerca de $80 \mathrm{~km}$ do continente. A plataforma continental exibe inclinação menor que $1^{\circ} \mathrm{com}$ pequenas variações ao longo de sua extensão, onde a maior variação ocorre na plataforma externa e na zona de quebra da plataforma $(80 \mathrm{~km}$ da linha de costa), com uma mudança abrupta de declividade para $8,5^{\circ}$ de inclinação.

Recomenda-se um estudo com dados batimétricos mais detalhados, bem como sua associação com dados de sísmica, de forma a tornar possível uma caracterização detalhada da morfologia da plataforma continental de Luís Correia.

\section{Agradecimentos}

Ao Laboratório de Geologia Marinha e Aplicada - LGMA/UFC por 
todo o apoio, ao Programa de Pósgraduação da Universidade Federal do Ceará, ao INPE pelas imagens de satélite e ao National Oceanic and Atmospheric Administration (NOAA) pelos dados batimétricos. Agradecemos também a CAPES, pois, o presente estudo foi realizado com apoio da Coordenação de Aperfeiçoamento de Pessoal de Nível Superior - Brasil (CAPES) Financiamento 001.

\section{REFERÊNCIAS}

AGUIAR, J. E., 2014. Contribuição ao estudo da mineralogia de sedimentos na plataforma continental dos Estados do Ceará, Piauí e Maranhão através da microscopia analítica SEM/EDS. Tese de doutorado, Pós-graduação em Ciências Marinhas Tropicais UFC. 173p.

Baptista Neto, J. A., Silva, C. G., 2004. Morfologia do Fundo Oceânico. In: Baptista Neto, J. A., Ponzi, V. R. A., Sichel, S. E. (Orgs) Introdução à Geologia Marinha. Interciência p.31-51.

Beltrami, C.V., Caldeira, J.L., Freitas, R.W., 1989. Análise sismoestratigráfica dos sedimentos Oligo/ Miocênicos da Bacia do Ceará águas profundas. Sintex - I Seminário de Interpretação Exploratória. Rio de Janeiro, Petrobras/Depex. p. 185194.
Beltrami, C. V., Alves, L. E. M., Feijó, F. J., 1994. Bacia do Ceará. Boletim de Geociências da Petrobras, 8:117-125.

Costa, M. P., Beltrami, C. V., Alves, L. E. M, 1989. A evolução tectonosedimentar e o Habitat do óleo da bacia do Ceará. Boletim Técnico da Petrobrás, 4:65-74.

Costa, M. P., Beltrami, C. V., Alves, L. E. M., 1990. A evolução tectonosedimentar e o Habitat do óleo da bacia do Ceará. Boletim Técnico da Petrobrás, 4: 65-74.

Dias, C. B., Barros, E. L., Morais, J. O., 2011. Granulados marinhos na Plataforma Continental N/NE do Brasil: Ensaio metodológico. In: XIII Congresso da Associação Brasileira de Estudos do Quaternário - ABEQUA. Rio de Janeiro.

Morais Neto, J. M., Neto, O. C. P., Lana, C. C., Zalán, P. V, 2003. Bacias sedimentares brasileiras - Bacia do Ceará. Fundação Paleontológica Phoenix, Aracaju, 57.

Suguio, K., 2003. Geologia Sedimentar. Edgard Blucher, São Paulo, 416 p.

Kennet J. P., 1982. Marine Geology. Prentice Hall Englewood Cliffs, New Jersey, 813 p. 